\title{
The pulmonary vascular complications of hereditary haemorrhagic telangiectasia
}

\author{
M.E. Faughnan**\#, J.T. Granton ${ }^{\uparrow}$ and L.H. Young ${ }^{+}$
}

\begin{abstract}
Hereditary haemorrhagic telangiectasia (HHT) is a rare autosomal dominant disorder, characterised by the presence of vascular malformations. The pulmonary vascular complications of HHT include pulmonary arteriovenous malformations, pulmonary hypertension associated with high-output heart failure and liver vascular malformations and, finally, pulmonary arterial hypertension secondary to HHT. In the present review, the authors describe the clinical presentation, diagnosis and management of all three pulmonary vascular presentations of HHT, as well as the underlying genetics and pathophysiology.
\end{abstract}

KEYWORDS: Hereditary haemorrhagic telangiectasia, pulmonary arterial hypertension, pulmonary arteriovenous malformation, pulmonary hypertension

$\mathrm{H}$ ereditary haemorrhagic telangiectasia (HHT) is a rare autosomal dominant disorder, with an estimated prevalence of 1 in 5000, characterised by vascular malformations in the nose, mouth, brain, lungs, liver and gastrointestinal (GI) tract, as well as on the skin. Pulmonary vascular complications of HHT are frequent and varied in presentation. Pulmonary arteriovenous malformations (PAVMs) are the most frequent complication, occurring in $15-45 \%$ of HHT patients, and can be treated preventatively. Pulmonary hypertension $(\mathrm{PH})$ is a recognised complication of liver vascular malformations (VMs) associated with high cardiac output, in HHT. PH can also occur in HHT patients without liver VMs, albeit more rarely, mimicking idiopathic pulmonary arterial hypertension (PAH). The clinical, molecular and pathophysiological aspects of all three pulmonary vascular presentations of HHT will be described.

The present review is part of a series of articles summarising the latest developments in pulmonary vascular disease [1], including reviews to date of current therapies for PAH [2-4] and of $\mathrm{PH}$ secondary to interstitial lung disease [5].

\section{PULMONARY ARTERIOVENOUS MALFORMATIONS}

\section{Clinical presentation and pathophysiology}

PAVMs are present in $15-45 \%$ of patients with HHT $[6,7]$ and HHT is the underlying cause in at least $80 \%$ of PAVMs. The prevalence of PAVMs appears to be higher in patients with endoglin mutation, in the range of $49-75 \%$, compared with $5-44 \%$ in patients with activin receptor-like kinase (ALK)-1 mutation [8-10]. Families with endoglin mutation also have a higher prevalence of cerebral arteriovenous malformations (AVMs) than those with ALK-1 mutation $[9,10]$. PAVMs are also reported in the small number of families with SMAD4 mutation, characteristic of the combined juvenile polyposis and HHT syndrome [11], but also found in approximately $3 \%$ of HHT families [12]. Basic research has uncovered alterations in transforming growth factor (TGF)- $\beta$ signalling, endothelial nitric oxide synthase activity and angiogenesis in HHT in recent years [13-16].

\section{AFFILIATIONS}

*Keenan Research Centre and Li Ka Shing Knowledge Institute, St Michael's Hospital,

\#Dept of Medicine, Division of Respirology, St Michael's Hospital, University of Toronto, and

-Dept of Medicine, Division of Respirology, University Health Network, University of Toronto, Toronto, ON, Canada.

+Dept of Medicine, Division of Cardiovascular Medicine, Yale Medical School, Yale University, New Haven, CT, USA.

CORRESPONDENCE

M.E. Faughnan

St Michael's Hospital

30 Bond Street

Toronto

ON

Canada, M5B-1W8

Fax: 14168645922

E-mail: faughnanm@

smh.toronto.on.ca

Received:

April 212008

Accepted after revision:

November 212008

SUPPORT STATEMENT

Financial support for this study was received by M.E. Faughnan from the Li Ka Shing Knowledge Institute of St Michael's Hospital and the Nelson Arthur Hyland Foundation (both

Toronto, ON, Canada).

STATEMENT OF INTEREST

None declared.

European Respiratory Journal Print ISSN 0903-1936 Online ISSN 1399-3003 
However, the exact cell biological mechanisms of how endoglin, ALK-1 or SMAD4 mutations actually lead to the development of AVMs remain uncertain.

Adults with untreated PAVMs are at risk of life-threatening haemorrhage and of neurological complications. In the larger series to date [17-20], previous stroke is reported in 10-36\%, transient ischaemic attack in 6-37\%, cerebral abscess in 8-19\% and massive haemoptysis or spontaneous haemothorax in 4$20 \%$ of patients. Similar complications occur in children [2123], although the rates are uncertain because of the smaller size of paediatric series and their inclusion of more severe cases with diffuse PAVMs.

The haemorrhagic complications of PAVMs can be lifethreatening, and the risk may be increased during pregnancy $[24,25]$, possibly due to increased cardiac output or due to changes in PAVM wall stability. Transient ischaemic attack and stroke are presumed to result from the paradoxical embolisation of asymptomatic leg vein thrombus though PAVMs to the left-sided arterial circulation. Alternatively, the thrombus can occasionally originate in situ in PAVMs, embolising to the left-sided circulation. Although patients with HHT are not clearly at increased risk of venous thromboembolism, those patients that do develop venous thromboembolism appear to have higher factor VIII levels [26]. Multiplicity of PAVMs has been associated with a higher risk of previous stroke in HHT patients [20]. Cerebral abscess presumably occurs secondary to paradoxical embolisation of bio-films of bacteria. The pathogens are often from an oral source [27] and the risk may be highest following dental procedures. Male sex and hypoxaemia also appear to increase the risk of cerebral abscess in patients with PAVMs [27]. PAVMs are also associated with migraine [28], particularly with aura [29], in HHT patients. There are no prospective cohort studies to precisely define the natural history of untreated PAVMs. Since experts believe that a "no treatment arm" would be unethical, our understanding of the complications of PAVMs are limited to these retrospective studies.

PAVMs in HHT are usually multiple (mean of three per patient) [30]. In approximately 5\% of cases, PAVMs are diffuse

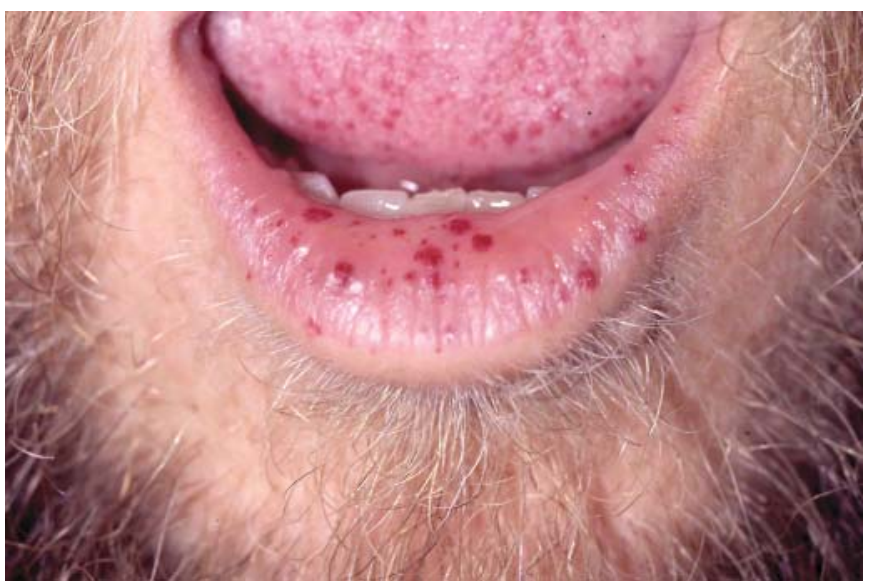

FIGURE 1. Typical telangiectasias in a 50-yr-old male with hereditary haemorrhagic telangiectasia (endoglin mutation), who also has pulmonary arteriovenous malformations. and innumerable [31, 32] and present special problems because of the difficulty in treating them. Approximately $80 \%$ of PAVMs in HHT are simple fistulas [33] with one or more feeding arteries. The remainder are complex, with feeding arteries from more than one segment and/or a septated or nidus-like structure. Figure 1 demonstrates typical lip and tongue telangiectasias and figures 2 and 3 demonstrate PAVMs, in a typical HHT family.

\section{Clinical evaluation}

Given the serious nature of the complications that can occur from untreated PAVMs, and the availability of safe and effective preventative therapy, most authors have recommended routine screening of all HHT patients for PAVMs [34]. The classical findings of PAVMs are cyanosis, clubbing and a pulmonary bruit. Although these findings are highly indicative of PAVMs, they are found in $<10 \%$ of HHT patients with PAVMs, so that clinical screening is clearly insufficient for detecting PAVMs in most HHT patients. Contrast echocardiography is the screening test of choice, with a sensitivity of $>90 \%[7,35]$ for detection of PAVMs in HHT patients. It involves no radiation exposure and is much more sensitive than oxygen shunt testing, oximetry, or chest radiography. Computed tomography $(\mathrm{CT})$ thorax is the current accepted diagnostic gold standard [22] and is used to confirm and measure the size of PAVMs in patients with positive contrast echocardiography. Standard pulmonary angiography has a lower resolution than current multidetector $\mathrm{CT}$ and is not performed as an initial diagnostic procedure. It is important to note that, with current multidetector CT technology, contrast enhancement is not required to detect even small PAVMs [30].

\section{Treatment}

Transcatheter embolotherapy is the current standard treatment for PAVMs. There is no longer any role for surgery in

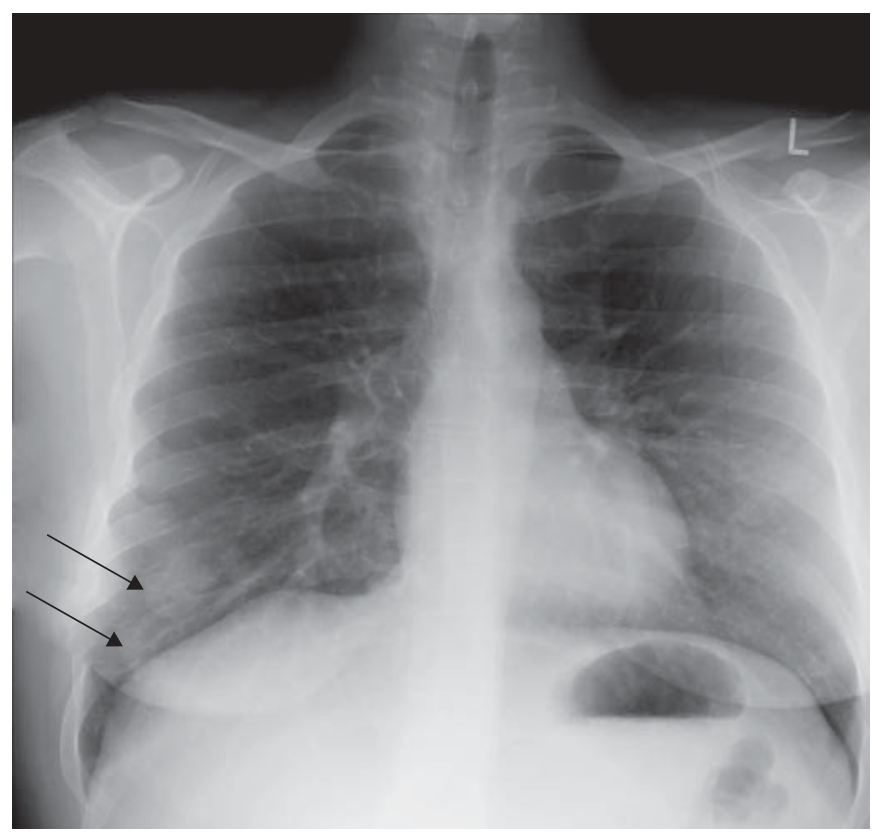

FIGURE 2. Chest radiograph of the 26-yr-old daughter of the patient shown in figure 1, demonstrating two pulmonary arteriovenous malformations in the right lung (arrows). L: left side. 


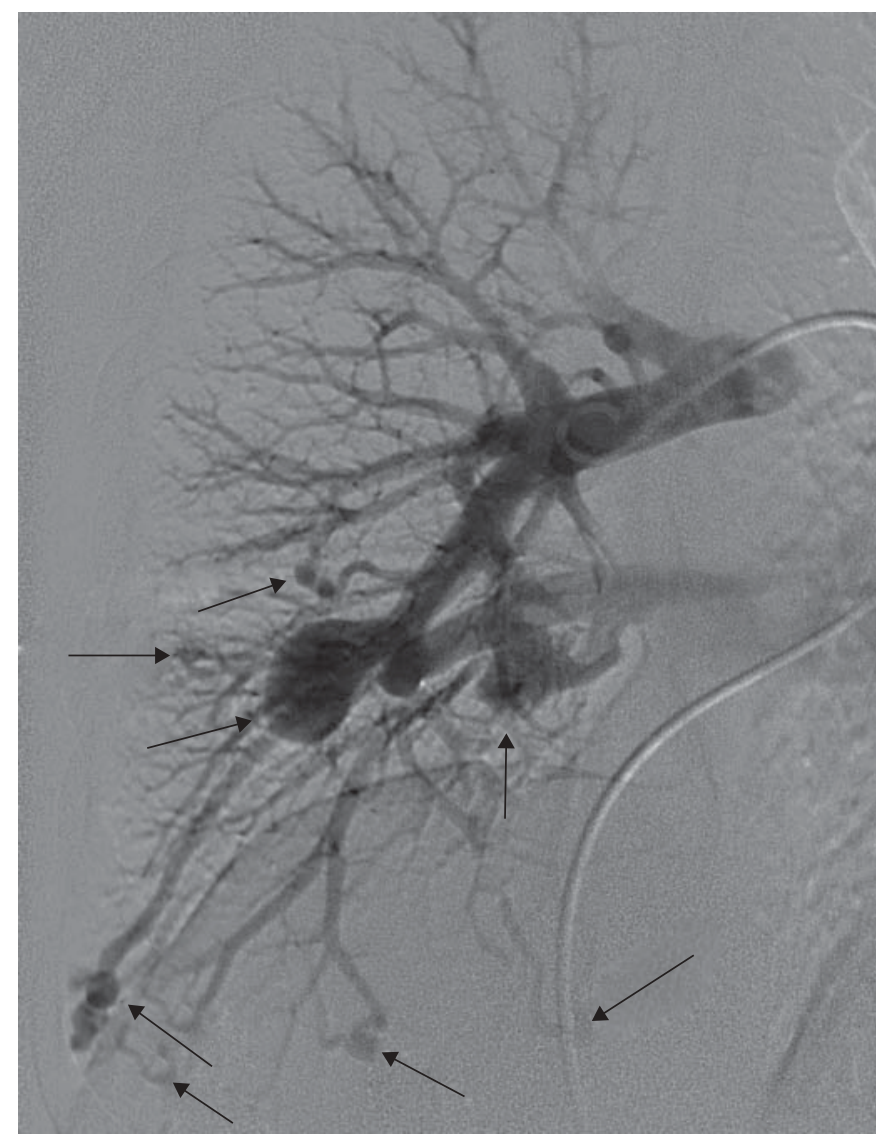

FIGURE 3. Right pulmonary angiogram of the same 26-yr-old patient as in figure 2, demonstrating multiple pulmonary arteriovenous malformations of variable size (arrows).

managing PAVMs. There have been several long-term, although uncontrolled, series demonstrating excellent procedural success (close to $100 \%$ ) and long-term efficacy (>83\%) for occlusion of PAVMs [18, 19, 36]. The most common complication of embolisation is pleuritic chest pain $[18,19,36]$, which is most often self-limited. There is a $<1 \%$ rate of paradoxical device embolisation [18, 19, 36], with distal complications occurring only very rarely. In the studies with at least 5 yrs follow-up, long-term complications from PAVMs were rare. When they occurred, complications were typically associated with residual significant (at least 3-mm) untreated PAVMs or reperfused PAVMs [30]. A feeding artery of at least $3 \mathrm{~mm}$ is currently the threshold for treatment of PAVMs, in most centres, as most complications of untreated PAVMs have been described in patients with a feeding artery of at least $3 \mathrm{~mm}$ [18], although some centres consider embolisation of smaller PAVMs. Since the reperfusion rate of PAVMs is approximately $10-17 \%[19,30]$, early and long-term follow-up are essential to detect PAVMs that need repeat embolisation. In addition, approximately $50 \%$ of patients have small detectable residual PAVMs [37], which should be followed and embolised when significant. Most authors recommend a minimum follow-up with CT at $1 \mathrm{yr}$ and every $3-5$ yrs thereafter [19, $30,37]$. It is important to note that the efficacy and safety data are all reported from centres with considerable expertise in PAVM embolotherapy. Thus, the efficacy and safety of these procedures may be less optimal in less experienced centres and, generally, patients should be referred to centres with substantial experience.

Certain precautions are also recommended to patients with PAVMs, even once they are embolised. Antibiotic prophylaxis for bacteraemic procedures continues to be routinely recommended to prevent cerebral abscess [6]. This is important as this complication does not seem to correlate with the feeding artery diameter of PAVMs and can occur even in patients with only $<3$-mm feeding arteries. In addition, use of intravenous air filters are typically recommended to prevent transient ischaemic attack from air embolism during i.v. infusions. Patients are also recommended to avoid SCUBA diving [37].

\section{PULMONARY HYPERTENSION}

In the context of HHT, it is important to recognise that PH may be categorised into two very distinct types (table 1). Most commonly, $\mathrm{PH}$ occurs in association with liver VMs, secondary to the high cardiac output, typically after the onset of left heart failure. These patients usually have mildly elevated left atrial pressures and low pulmonary vascular resistance (PVR). Less commonly, patients have elevated pulmonary artery pressures, normal left atrial pressure, normal or reduced cardiac output and significantly increased PVR. These latter patients have $\mathrm{PAH}$ and have a true pulmonary arteriopathy (see later section). The key differentiating variable is the transpulmonary gradient (TPG; mean pulmonary artery pressure $\left(\bar{P}_{\mathrm{pa}}\right)$ minus an estimate of left atrial pressure; normally $<12 \mathrm{mmHg}$ ). The TPG is normal in the high-output cardiac failure-related PH but increased in patients with PAH.

\section{PH and high-output heart failure}

In patients with HHT, PH most often results from the high pulmonary blood flow and left heart failure that accompanies the high cardiac output state associated with liver VMs. Mutations in the ALK-1 gene are typically present in these patients, although cases of liver VMs in HHT due to endoglin mutations have also been reported [8, 9, 38]. Liver VMs are detected in as many as $40-75 \%$ of patients with HHT using sensitive imaging techniques (fig. 4) [39, 40], but most are small and do not lead to symptoms. However, more significant liver VMs do cause symptoms in $5-8 \%$ of patients with HHT

\begin{tabular}{|c|c|c|c|c|c|c|}
\hline TABLE 1 & $\begin{array}{l}\text { Ha } \\
\text { ha } \\
\text { hyl }\end{array}$ & emor & $\begin{array}{l}\text { amic } \\
\text { gic t } \\
\text { in }(P\end{array}$ & $\begin{array}{l}\text { rofiles in patier } \\
\text { angiectasia anc }\end{array}$ & $\begin{array}{l}\text { s with } \\
\text { oulmo }\end{array}$ & areditary \\
\hline Profile & & $\bar{P}$ pa & co & PAOP & TPG & PVR \\
\hline $\begin{array}{l}\mathrm{PH}, \text { high flow, } \\
\text { failure }\end{array}$ & & $\uparrow$ & $\uparrow \uparrow$ & High-normal or $\uparrow$ & Normal & Normal \\
\hline PAH & & $\uparrow \uparrow$ & $\downarrow$ & Normal & $\uparrow$ & $\uparrow \uparrow$ \\
\hline
\end{tabular}




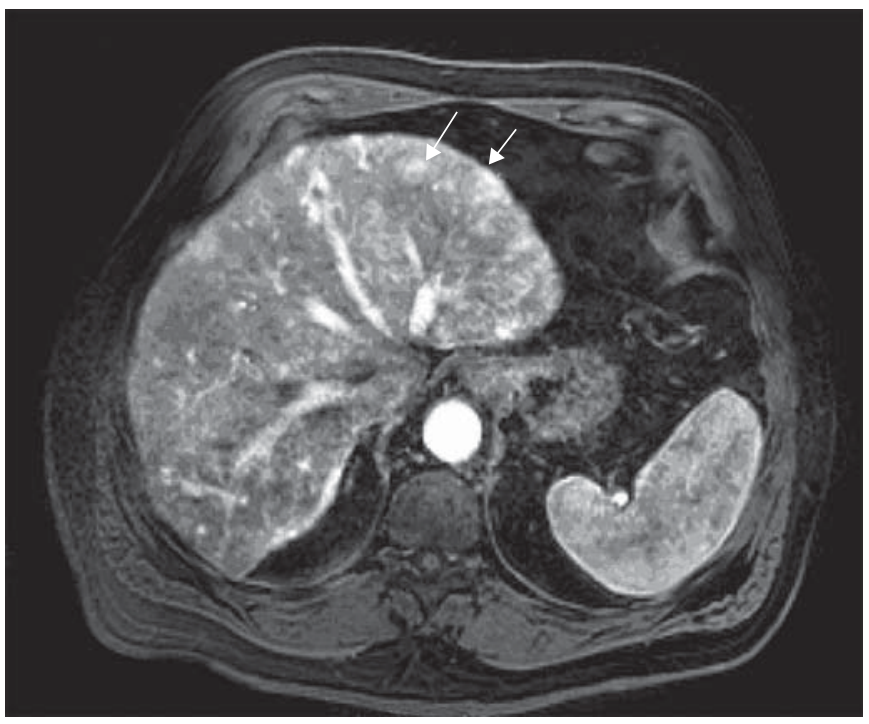

FIGURE 4. Gadolinium-enhanced T1-weighted magnetic resonance image of diffuse liver vascular malformations. There is evidence of diffuse telangiectasia and confluent vascular malformations (arrows). In addition, this arterial phase image shows early enhancement of the hepatic veins, compatible with hepatic artery to hepatic vein shunting.

[41-43]. Most commonly, these patients have exertional dyspnoea and fatigue, palpitations and peripheral oedema related to high-output cardiac failure [41, 42].

Liver VMs are associated less commonly with a variety of other symptoms. Shunting of blood from the hepatic artery to veins causes steal syndromes with abdominal pain from either biliary or mesenteric ischaemia [41-43]. Communications between the hepatic artery and portal veins can result in portal hypertension with gastrointestinal bleeding or ascites [41, 42]. Portal vein to hepatic vein shunts predispose to hepatic encephalopathy manifested by confusion and asterixis [41, 42]. CT scanning generally identifies these vascular abnormalities, but does not specifically predict the predominant clinical manifestations in individual patients [44]. Although most patients initially manifest one symptom type, clinical overlap can occur with the development of biliary ischaemia or hepatic encephalopathy in heart failure patients [41].

The most common clinical manifestation of liver VMs is highoutput heart failure [45], accounting for over $80 \%$ of patients in larger series [41, 42, 45]. For unknown reasons, heart failure occurs much more commonly in females than in males [41]. Patients often develop symptoms of heart failure in their seventh decade of life, although symptoms can develop in females during pregnancy [46]. Heart failure occurs in patients with two- to three-fold elevations in cardiac output due to elevated hepatic blood flow, which can approach 5-10 L· $\mathrm{min}^{-1}$ [41]. Shunting of blood through the liver sometimes results in the oxygen content of hepatic venous blood approaching that of arterial blood. A large step-up between the mid inferior vena cava and right atrium is often present and indicates significant hepatic artery to vein shunting. The high flow through the liver also results in elevated central mixed venous saturations that mimic those seen with atrial septal defects and other large intra-cardiac left-to-right shunts.

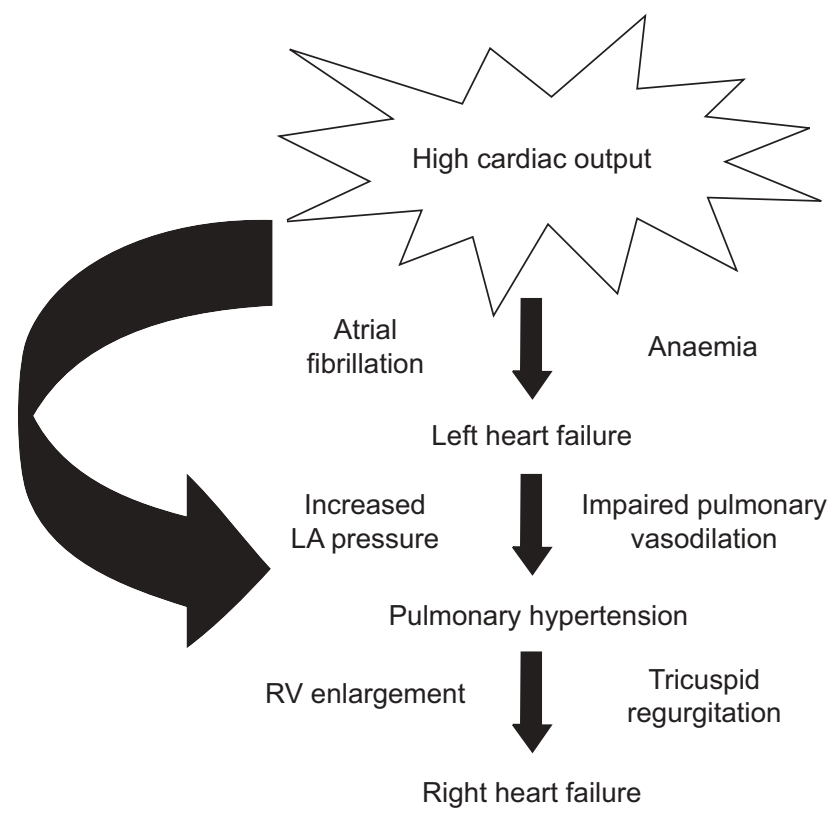

FIGURE 5. Pathophysiology of pulmonary hypertension in patients with hereditary haemorrhagic telangiectasia and liver vascular malformations. LA: left atrial; RV: right ventricle.

\section{Pathophysiology}

In healthy patients with liver VMs and high cardiac output, the pulmonary vasculature dilates adequately to maintain normal pulmonary artery pressures. The mechanisms responsible for the development of left ventricular failure and $\mathrm{PH}$ in patients with high cardiac output are outlined in figure 5. PH most often occurs in patients with liver VMs from the high pulmonary blood flow in combination with an elevation in pulmonary venous pressure from left ventricular failure [41]. Importantly, left ventricular failure occurs in patients with liver VMs in the absence of overt left ventricular systolic dysfunction [41]. Elevation in pulmonary capillary wedge pressures [41] reflects the combination of high pulmonary venous flow and left ventricular diastolic dysfunction.

Symptoms of heart failure are often precipitated by the development of atrial fibrillation or severe anaemia [41]. Patients with liver VMs and high cardiac output are predisposed to atrial fibrillation, because they often have left atrial enlargement. The loss of atrial contraction with the onset of atrial fibrillation impairs ventricular filling and triggers haemodynamic decompensation in susceptible patients. Severe anaemia also reduces systemic oxygen delivery and exacerbates the symptoms of heart failure [42]. The extent to which remodelling of the pulmonary vasculature also occurs with chronic high flow from liver VMs is uncertain. Nonetheless, once pulmonary arterial pressures are elevated, the combination of volume and pressure overload potentially strains the right ventricle (RV) leading to right ventricular enlargement and contractile dysfunction, secondary tricuspid regurgitation and right heart failure [41-43].

\section{Evaluation of high-output heart failure}

$\mathrm{PH}$ is often detected first by echocardiography during the evaluation of patients with HHT who are experiencing 
exertional dyspnoea. Such patients should always undergo evaluation for liver VMs, since high cardiac output is the most common cause of $\mathrm{PH}$ in HHT and is potentially improved with therapy. In most cases, clinical features readily distinguish $\mathrm{PH}$ associated with high-output heart failure from PAH associated with HHT. In high-output heart failure, bedside evaluation typically reveals a wide arterial pulse pressure with a low diastolic pressure due to the reduced systemic vascular resistance with rapid run-off of the cardiac stroke volume through the liver VMs [42]. Pulses are bounding, the precordium is active and a systolic ejection murmur is readily detected at the left sternal border [41]. Auscultation of the abdomen generally reveals a hepatic bruit and the liver is often pulsatile. Thus, the triad of a wide arterial pulse pressure, systolic murmur and liver bruit is virtually diagnostic for liver VMs with high output in patients with HHT.

Doppler echocardiography is a useful diagnostic tool in patients with suspected high-output cardiac failure and secondary PH. Although left ventricular systolic function is normal, left ventricle size is at the upper limits of normal and left atrial enlargement is almost always present. Doppler flow velocities in the left ventricular outflow track and aortic valve are often elevated, sometimes incorrectly interpreted as suggestive of aortic stenosis. The right ventricular findings vary according to the severity and duration of disease. Early in the disease, the RV appears normal, but later the RV enlarges. In patients with significant $\mathrm{PH}$ the $\mathrm{RV}$ can develop contractile dysfunction and tricuspid regurgitation. In patients with $\mathrm{PH}$, the Doppler-derived measurement of the tricuspid regurgitant jet provides a reasonable estimate of peak RV and pulmonary arterial systolic pressure. The development of a D-shaped septum is an ominous sign, but is much less common than in patients with PAH.

Right heart catheterisation is the gold standard for the diagnosis of $\mathrm{PH}$ associated with liver VMs [41, 47]. High cardiac output, elevated pulmonary capillary wedge pressures and a normal PVR readily distinguish high-output failure from patients with PAH (table 1). Specifically, PVR is typically normal even in the presence of moderate PH. In patients with more advanced disease, or those who have been treated with diuretics, the right heart catheterisation findings are often less typical and more difficult to interpret. Diuretics lower pulmonary capillary wedge pressures, but the cardiac output remains elevated and the PVR is often still low or normal.

\section{Treatment}

Treatment of high cardiac output failure in patients with liver VMs is directed at the treatment of left heart failure, anaemia and atrial fibrillation [41, 42]. Aggressive treatment with diuretics is a mainstay of treatment in that it reduces the pulmonary venous pressures and often significantly lowers the pulmonary artery pressures. Correction of severe anaemia is essential to minimise the stress on the heart [41] and many patients are considerably less symptomatic when the haemoglobin concentration is maintained greater than $10 \mathrm{~g} \cdot \mathrm{dL}^{-1}$. Since iron deficiency often results from recurrent epistaxis or gastrointestinal bleeding from telangiectasias, aggressive iron replacement and sometimes blood transfusion are required. In patients with atrial fibrillation, an aggressive approach to cardioversion and the subsequent maintenance of sinus rhythm with anti-arrhythmic therapy should be considered.

The utility of pulmonary vasodilators in the treatment of $\mathrm{PH}$ associated with liver VMs is uncertain. There are important theoretical concerns that any systemic vasodilatation would have adverse consequences on left heart failure. Thus, the use of pulmonary vasodilators should be limited to patients with PAH (see later section) [48].

Surgical hepatic artery ligation [49] and percutaneous hepatic artery embolisation [50] have been used at some centres for the treatment of liver VMs. However, these interventions can lead to the development of biliary ischaemia and in some cases serious hepatic necrosis [41, 42]. Thus, sub-selective hepatic artery embolisation is reserved only for highly selected patients who have failed medical therapy and who are not considered candidates for liver transplantation [42, 47]. Liver transplantation has been used for highly symptomatic individuals with high-output heart failure due to extensive liver VMs [51, 52]. Excellent success in reducing cardiac output and alleviating symptoms has been reported in some patients. Although patients with severe $\mathrm{PH}$, right ventricular dysfunction or severe tricuspid regurgitation are typically excluded from transplant consideration, those with mild $\mathrm{PH}$, normal PVR, high cardiac output and normal right ventricular function are potentially candidates for transplantation. Due to the inherent risks of surgery and the long-term immunosuppressive therapy after liver transplantation, alternatives for the treatment of high-output failure would be highly desirable. One recent case report raised the possibility that antiangiogenic therapy with anti-vascular endothelial growth factor antibody (bevacizumab) might be effective in reducing the size of liver VMs and useful in the treatment of patients with high-output heart failure [53]. Additional investigations of the long-term risks and benefits of this approach and of other anti-angiogenic therapies are required.

\section{PAH in HHT}

Although rare, $\mathrm{PAH}$ is increasingly recognised as a complication of HHT $[13,54]$. Symptoms of fatigue and breathlessness are relatively nonspecific and could potentially be related to anaemia, PAVMs or liver VMs in HHT patients. However, the development of unexplained shortness of breath with features indicating right heart pressure or volume overload should prompt evaluation for the presence of PAH.

The exact prevalence of PAH in the population of HHT patients, however, has not been systematically evaluated. In a recent genotype-phenotype study of 111 patients with HHT, no case of PAH was documented [55]. However there did not appear to be a systematic evaluation of each patient, making it difficult to determine how many of that cohort actually underwent echocardiographic screening for $\mathrm{PH}$. In a recent echocardiographic study of 68 patients with $\mathrm{PAH}$, elevated tricuspid regurgitant Doppler velocities indicative of right ventricular systolic pressure was present in nine out of 44 of evaluable patients ( 24 patients could not have peak pulmonary pressure measured) [56]. Three were family members of a patient with known PAH, one patient had undiagnosed mitral valve disease and others had liver VMs. Echocardiographic estimates of pulmonary pressure are of limited value, 
particularly in patients who may have high cardiac output [57] Invasive haemodynamics were not obtained and consequently the actual prevalence of PAH in the study cohort is not known.

\section{Genetics}

Gene mutations have been described in some cases of PAH. Mutations in the bone morphogenetic protein receptor (BMPR) type II are responsible for the majority of patients with familial $\mathrm{PAH}$ and occasionally for sporadic forms of the disease [58]. Haploinsufficiency for BMPR-II is felt to be the predominant molecular mechanism underlying the familial predisposition to $\mathrm{PH}$ [59]. The prevalence of mutations or polymorphisms in the BMPR-II gene in the general population is probably very low. However, in kindred studies of patients with $\mathrm{PAH}$, the presence of a BMPR-II mutation confers an increased, but not absolute, risk of developing PAH. To this end it has been proposed that a "two-hit" phenomenon is required in "at risk" individuals before PAH becomes manifest [60]. In the presence of a BMPR-II mutation, however, PAH, when it does occur, appears more severe than in patients who do not carry a BMPR-II mutation. In a recent study, 68 BMPR-II carriers with $\mathrm{PAH}$ were compared with 155 noncarriers with PAH [61]. Those with a BMPR-II mutation were younger at diagnosis $(36.5 \pm 14.5$ versus $46.0 \pm 16.1$ yrs; $\mathrm{p}<0.0001)$ and had worse haemodynamics and shorter survival or time to lung transplantation.

Mutations in BMPR-II have not been found in patients with HHT-related PAH (HHT-PAH). However mutations in ALK-1 have been implicated. Since the seminal publication by TREMBATH et al. [62], a variety of mutations in the ALK-1 gene appear to predispose patients with HHT to the development of PAH $[54,62,63]$. In contrast, mutation in the endoglin gene in HHT-PAH patients is uncommon and may be attributable to other causes such as pulmonary embolism, exposure to anorexogens, or liver VMs $[56,64]$. Although an initial report suggested that there was an age-related reduction in endoglin in PAH patients with either HHT1 or HHT2 [65], this was not confirmed in a subsequent study [13], demonstrating that the level of newly synthesised endoglin protein, as measured by metabolic labelling, was not altered in 61 patients with HHT2 and $\mathrm{PH}$.

The association between mutations in the ALK-1 gene and HHT-PAH highlights the potential relevance of perturbations in the TGF- $\beta$ signalling pathway on angiogenesis and endothelial function/repair [59, 66, 67]. Although ALK-1 and BMPR-II operate on different TGF- $\beta$ receptors, they share a common intracellular intermediary pathway through activation of SMADs 1/5/8 [68]. Further evidence for the importance of TGF- $\beta$ signalling stems from observations that alterations in exons 8 and 10 of the ALK-1 gene appear to be common in patients with PAH and HHT [13]. Mutations in exon 10 are relevant in that they have been demonstrated to occur within a conserved carboxyl-terminal region of ALK-1 (the non-activating non-downregulating box (NANDOR BOX)), an alteration that may have effects on TGF- $\beta$-induced receptor signalling $[54,63,66]$. The finding that juvenile polyposis is associated with mutations in either SMAD4, as in the juvenile polyposishereditary telangiectasia syndrome [11], or BMPR-IA [69] further supports the importance of BMPR signalling and the potential link between HHT and PAH [69].
Intimal hyperplasia, medial thickening, in situ thrombosis and plexiform lesions characterise the arteriopathy seen in idiopathic and other forms of PAH, including HHT-PAH. There is also one report of pulmonary capillary haemangiomatosis in a patient with HHT [70]. Although the authors did not report upon this patient's genotype, they commented that there was no difference in ALK-1 expression in diseased versus normal endothelial cells. Given the angioproliferative features of pulmonary capillary haemangiomatosis, the potential link between it and HHT is intriguing but, fortunately, seems rare.

\section{Haemodynamics}

The typical haemodynamic profile of $\mathrm{PAH}$ is that of an elevation of $\bar{P}$ pa (defined as $>25 \mathrm{mmHg}$ at rest and $>30 \mathrm{mmHg}$ with exercise) and normal left atrial pressure, and is further characterised by a low cardiac output and elevated PVR. These findings contrast with the haemodynamic findings described in PH secondary to liver VMs (table 1) [54, $62,63]$. In the few reports of HHT patients with PAH that have provided haemodynamic data, the haemodynamic pattern has been one of a low cardiac output, high PVR state as seen in idiopathic PAH [54, 62, 63]. Therefore, these patients are likely to share both the haemodynamics and natural history of progressive right heart failure that is seen in their idiopathic PAH counterparts.

\section{Right heart failure}

The presence of right heart dysfunction and high RV afterload may present unique challenges in the patient with HHT and PAH. In the setting of GI bleeding and/or epistaxis, the hypovolaemia can precipitate low cardiac output. Bleeding can also result in anaemia, which decreases oxygen delivery and increases cardiac demand that might not be able to be met by a failing RV.

Special considerations are warranted with regard to the unusual patients with PAVMs and PAH. Since PAVMs unload the RV, embolisation of PAVMs in the patient with $\mathrm{PAH}$ theoretically can lead to an increase in right ventricular afterload and precipitate right heart failure. Little reassurance about this possibility is provided by a recent publication of pulmonary embolisation in 143 patients with PAVMs [71]. In their report, SHOVLIN et al. [71] found no elevation in pulmonary pressures or ensuing right heart failure following embolisation. However, as pointed out in the accompanying editorial, patients with $\mathrm{PAH}$ were not included in this report. Indeed, four patients with established $\mathrm{PAH}$ were excluded from embolisation. Thus, it remains critical to identify patients with low cardiac output and reduced RV function who might develop worsening in RV function after embolisation. Interestingly, there is a reported case of a male infant with $\mathrm{PAH}$, who later manifested HHT, with the development of PAVMs associated with a reduction in $\bar{P}$ pa and improvement in the PVR [72]. Presumably the development of PAVMs led to a reduction in $\mathrm{RV}$ afterload.

\section{Treatment}

Several medical treatment strategies have been shown to be efficacious in PAH and one would anticipate that they would be useful in the management of HHT-PAH. In controlled clinical trials, parenteral prostanoids, endothelin inhibitors and 
phosphodiesterase inhibitors have been shown to improve haemodynamics, exercise capacity and symptoms in patients with PAH from a variety of causes [2-4, 73]. Although these therapies have been shown to improve outcome compared with historical cohorts, only flolan has been shown to improve survival within a controlled clinical trial [74]. It is interesting that, irrespective of the cause of $\mathrm{PAH}$, most of these therapies have been shown to be of benefit, perhaps implying commonalities in pathophysiology as it relates to the prostaglandin, endothelin and nitric oxide pathways in PAH. In this regard, it is not surprising that there are cases showing benefit of these therapies in HHT patients with PAH.

There are no systematic reports evaluating outcomes of patients with HHT-PAH. However, one would anticipate that these patients share the poor prognosis of other patients with PAH. Consequently, there is an imperative to provide treatment options to these patients. At present, the experience with medical treatments is sparse and limited to case reports. MINAI et al. [75] reported a patient with HHT-PAH without a detectable ALK-1 or endoglin mutation treated for PAH over a period of $10 \mathrm{yrs}$. Interestingly, this patient demonstrated an initial acute haemodynamic response to calcium channel blockers with a reduction in $\bar{P}$ pa from 110 to $58 \mathrm{mmHg}$, and stabilisation of $\bar{P}_{\text {pa }}$ with nifedipine over a 5 -yr period. Subsequently, epoprostenol and then treprostinil were used intravenously over the next 4 yrs. Over the period of observation there was an improvement in functional capacity and symptoms. Acute response to vasodilators in HHT-PAH has not been reported previously [62]. Thus, there is probably no role for the use of calcium channel blockers in this population. Therefore, the case report by MiNAI et al. [75] not withstanding, the current authors do not advocate for the routine use of vasodilator testing or use of calcium channel blockers in patients with HHT-PAH. In another report, bosentan (a nonselective endothelin inhibitor) was shown to improve haemodynamics, exercise capacity (as measured by 6min walk distance) and pro-brain natriuretic peptide levels in two patients with HHT-PAH [48].

Owing to the rarity of HHT-PAH, prospective randomised trials are unlikely to be feasible. At present, many jurisdictions are not able to use these medications beyond certain diagnostic causes of PAH. Carefully conducted case series that evaluate changes in haemodynamics, exercise capacity, symptoms and quality-of-life measures with therapy hopefully will provide evidence to support the efficacy of these often costly therapies.

\section{CONCLUSIONS}

Advances in the understanding of hereditary haemorrhagic telangiectasia have highlighted the importance of pulmonary vascular disease in these patients and, in turn, have led to specific therapies to treat the pulmonary manifestations of this disease. Early screening and embolisation for pulmonary arteriovenous malformations in hereditary haemorrhagic telangiectasia is recommended to prevent the haemorrhagic and neurological complications of pulmonary arteriovenous malformations. In patients with pulmonary hypertension, distinguishing between pulmonary hypertension associated with liver vascular malformations and pulmonary arterial hypertension is critical. Formal haemodynamic assessment of patients with pulmonary hypertension and investigations for liver vascular malformations should be completed for prognostic reasons and to help guide treatment.

\section{REFERENCES}

1 Hoeper MM, Dinh-Xuan AT. Pulmonary hypertension: basic concepts and practical management. Eur Respir J 2008; 31: 236-237.

2 Dupuis J, Hoeper MM. Endothelin receptor antagonists in pulmonary arterial hypertension. Eur Respir J 2008; 31: 407-415.

3 Gomberg-Maitland M, Olschewski H. Prostacyclin therapies for the treatment of pulmonary arterial hypertension. Eur Respir J 2008; 31: 891-901.

4 Wilkins MR, Wharton J, Grimminger F, Ghofrani HA. Phosphodiesterase inhibitors for the treatment of pulmonary hypertension. Eur Respir J 2008; 32: 198-209.

5 Behr J, Ryu JH. Pulmonary hypertension in interstitial lung disease. Eur Respir J 2008; 31: 1357-1367.

6 Gossage JR, Kanj G. Pulmonary arteriovenous malformations. A state of the art review. Am J Respir Crit Care Med 1998; 158: 643-661.

7 Cottin V, Plauchu H, Bayle JY, Barthelet M, Revel D, Cordier JF. Pulmonary arteriovenous malformations in patients with hereditary hemorrhagic telangiectasia. Am J Respir Crit Care Med 2004; 169: 994-1000.

8 Lesca G, Olivieri C, Burnichon N, et al. Genotypephenotype correlations in hereditary hemorrhagic telangiectasia: data from the French-Italian HHT network. Genet Med 2007; 9: 14-22.

9 Letteboer TG, Mager JJ, Snijder RJ, et al. Genotypephenotype relationship in hereditary haemorrhagic telangiectasia. J Med Genet 2006; 43: 371-377.

10 Sabba C, Pasculli G, Lenato GM, et al. Hereditary hemorrhagic telangiectasia: clinical features in ENG and ALK1 mutation carriers. J Thromb Haemost 2007; 5: 1149-1157.

11 Gallione CJ, Repetto GM, Legius E, et al. A combined syndrome of juvenile polyposis and hereditary haemorrhagic telangiectasia associated with mutations in MADH4 (SMAD4). Lancet 2004; 363: 852-859.

12 Gallione CJ, Richards JA, Letteboer TG, et al. SMAD4 mutations found in unselected HHT patients. J Med Genet 2006; 43: 793-797.

13 Abdalla SA, Letarte M. Hereditary haemorrhagic telangiectasia: current views on genetics and mechanisms of disease. J Med Genet 2006; 43: 97-110.

14 Santibanez JF, Letamendia A, Perez-Barriocanal F, et al. Endoglin increases eNOS expression by modulating Smad2 protein levels and Smad2-dependent TGF- $\beta$ signaling. J Cell Physiol 2007; 210: 456-468.

15 Duwel A, Eleno N, Jerkic M, et al. Reduced tumor growth and angiogenesis in endoglin-haploinsufficient mice. Tumour Biol 2007; 28: 1-8.

16 Jerkic M, Rodriguez-Barbero A, Prieto M, et al. Reduced angiogenic responses in adult endoglin heterozygous mice. Cardiovasc Res 2006; 69: 845-854.

17 Cottin V, Chinet T, Lavole A, et al. Pulmonary arteriovenous malformations in hereditary hemorrhagic telangiectasia: a series of 126 patients. Medicine (Baltimore) 2007; 86: 1-17. 
18 White RI Jr, Lynch-Nyhan A, Terry P, et al. Pulmonary arteriovenous malformations: techniques and long-term outcome of embolotherapy. Radiology 1988; 169: 663-669.

19 Mager JJ, Overtoom TT, Blauw H, Lammers JW, Westermann CJ. Embolotherapy of pulmonary arteriovenous malformations: long-term results in 112 patients. J Vasc Interv Radiol 2004; 15: 451-456.

20 Moussouttas M, Fayad P, Rosenblatt M, et al. Pulmonary arteriovenous malformations: cerebral ischemia and neurologic manifestations. Neurology 2000; 55: 959-964.

21 Faughnan ME, Thabet A, Mei-Zahav M, et al. Pulmonary arteriovenous malformations in children: outcomes of transcatheter embolotherapy. J Pediatr 2004; 145: 826-831.

22 Curie A, Lesca G, Cottin V, et al. Long-term follow-up in 12 children with pulmonary arteriovenous malformations: confirmation of hereditary hemorrhagic telangiectasia in all cases. J Pediatr 2007; 151: 299-306.

23 Mei-Zahav M, Letarte M, Faughnan ME, Abdalla SA, Cymerman U, MacLusky IB. Symptomatic children with hereditary hemorrhagic telangiectasia: a pediatric center experience. Arch Pediatr Adolesc Med 2006; 160: 596-601.

24 Ference BA, Shannon TM, White RI Jr, Zawin M, Burdge CM. Life-threatening pulmonary hemorrhage with pulmonary arteriovenous malformations and hereditary hemorrhagic telangiectasia. Chest 1994; 106: 1387-1390.

25 Shovlin CL, Winstock AR, Peters AM, Jackson JE, Hughes JM. Medical complications of pregnancy in hereditary haemorrhagic telangiectasia. QJM 1995; 88: 879-887.

26 Shovlin CL, Sulaiman NL, Govani FS, Jackson JE, Begbie ME. Elevated factor VIII in hereditary haemorrhagic telangiectasia (HHT): association with venous thromboembolism. Thromb Haemost 2007; 98: 1031-1039.

27 Shovlin CL, Jackson JE, Bamford KB, et al. Primary determinants of ischaemic stroke/brain abscess risks are independent of severity of pulmonary arteriovenous malformations in hereditary haemorrhagic telangiectasia. Thorax 2008; 63: 259-266.

28 Post MC, Letteboer TG, Mager JJ, Plokker TH, Kelder JC, Westermann CJ. A pulmonary right-to-left shunt in patients with hereditary hemorrhagic telangiectasia is associated with an increased prevalence of migraine. Chest 2005; 128: 2485-2489.

29 Thenganatt J, Schneiderman J, Hyland RH, Edmeads J, Mandzia JL, Faughnan ME. Migraines linked to intrapulmonary right-to-left shunt. Headache 2006; 46: 439-443.

30 Pollak JS, Saluja S, Thabet A, Henderson KJ, Denbow N, White RI Jr. Clinical and anatomic outcomes after embolotherapy of pulmonary arteriovenous malformations. J Vasc Interv Radiol 2006; 17: 35-44.

31 Pierucci P, Murphy J, Henderson KJ, Chyun DA, White RI Jr. New definition and natural history of patients with diffuse pulmonary arteriovenous malformations: twentyseven-year experience. Chest 2008; 133: 653-661.

32 Faughnan ME, Lui YW, Wirth JA, et al. Diffuse pulmonary arteriovenous malformations: characteristics and prognosis. Chest 2000; 117: 31-38.

33 White RI Jr, Mitchell SE, Barth KH, et al. Angioarchitecture of pulmonary arteriovenous malformations: an important consideration before embolotherapy. AJR Am J Roentgenol 1983; 140: 681-686.
34 Gossage JR. Primary pulmonary hypertension or portopulmonary hypertension? Chest 1998; 114: 1224-1225.

35 Nanthakumar K, Graham AT, Robinson TI, et al. Contrast echocardiography for detection of pulmonary arteriovenous malformations. Am Heart J 2001; 141: 243-246.

36 Lee DW, White RI Jr, Egglin TK, et al. Embolotherapy of large pulmonary arteriovenous malformations: long-term results. Ann Thorac Surg 1997; 64: 930-939.

37 Lee WL, Graham AF, Pugash RA, et al. Contrast echocardiography remains positive after treatment of pulmonary arteriovenous malformations. Chest 2003; 123: 351-358.

38 Argyriou L, Pfitzmann R, Wehner LE, et al. ALK-1 mutations in liver transplanted patients with hereditary hemorrhagic telangiectasia. Liver Transpl 2005; 11: 1132-1135.

39 Buonamico P, Suppressa P, Lenato GM, et al. Liver involvement in a large cohort of patients with hereditary hemorrhagic telangiectasia: echo-color-Doppler versus multislice computed tomography study. J Hepatol 2008; 48: 811-820.

40 Buscarini E, Buscarini L, Danesino C, et al. Hepatic vascular malformations in hereditary hemorrhagic telangiectasia: Doppler sonographic screening in a large family. J Hepatol 1997; 26: 111-118.

41 Garcia-Tsao G, Korzenik JR, Young L, et al. Liver disease in patients with hereditary hemorrhagic telangiectasia. $N$ Engl J Med 2000; 343: 931-936.

42 Garcia-Tsao G. Liver involvement in hereditary hemorrhagic telangiectasia (HHT). J Hepatol 2007; 46: 499-507.

43 Larson AM. Liver disease in hereditary hemorrhagic telangiectasia. J Clin Gastroenterol 2003; 36: 149-158.

44 Wu JS, Saluja S, Garcia-Tsao G, Chong A, Henderson KJ, White RI Jr. Liver involvement in hereditary hemorrhagic telangiectasia: CT and clinical findings do not correlate in symptomatic patients. AJR Am J Roentgenol 2006; 187: W399-W405.

45 Montejo Baranda M, Perez M, De Andres J, De la Hoz C, Merino J, Aguirre C. High out-put congestive heart failure as first manifestation of Osler-Weber-Rendu disease. Angiology 1984; 35: 568-576.

46 Livneh A, Langevitz P, Morag B, Catania A, Pras M. Functionally reversible hepatic arteriovenous fistulas during pregnancy in patients with hereditary hemorrhagic telangiectasia. South Med J 1988; 81: 1047-1049.

47 Buscarini E, Plauchu H, Garcia Tsao G, et al. Liver involvement in hereditary hemorrhagic telangiectasia: consensus recommendations. Liver Int 2006; 26: 1040-1046.

48 Bonderman D, Nowotny R, Skoro-Sajer N, Adlbrecht C, Lang IM. Bosentan therapy for pulmonary arterial hypertension associated with hereditary haemorrhagic telangiectasia. Eur J Clin Invest 2006; 36: Suppl. 3, 71-72.

49 Koscielny A, Willinek WA, Hirner A, Wolff M. Treatment of high output cardiac failure by flow-adapted hepatic artery banding (FHAB) in patients with hereditary hemorrhagic telangiectasia. J Gastrointest Surg 2008; 12: 872-876.

50 Chavan A, Caselitz M, Gratz KF, et al. Hepatic artery embolization for treatment of patients with hereditary hemorrhagic telangiectasia and symptomatic hepatic vascular malformations. Eur Radiol 2004; 14: 2079-2085.

51 Scelzo C, Greco S, Bonanni L, et al. The role of liver transplantation in the treatment of hereditary hemorrhagic 
telangiectasia: a short literature review. Transplant Proc 2007; 39: 2045-2047.

52 Lerut J, Orlando G, Adam R, et al. Liver transplantation for hereditary hemorrhagic telangiectasia: report of the European liver transplant registry. Ann Surg 2006; 244: 854-862.

53 Mitchell A, Adams LA, MacQuillan G, Tibballs J, vanden Driesen R, Delriviere L. Bevacizumab reverses need for liver transplantation in hereditary hemorrhagic telangiectasia. Liver Transpl 2008; 14: 210-213.

54 Abdalla SA, Gallione CJ, Barst RJ, et al. Primary pulmonary hypertension in families with hereditary haemorrhagic telangiectasia. Eur Respir J 2004; 23: 373-377.

55 Bayrak-Toydemir P, McDonald J, et al. Genotype-phenotype correlation in hereditary hemorrhagic telangiectasia: mutations and manifestations. Am J Med Genet A 2006; 140: 463-470.

56 Olivieri C, Lanzarini L, Pagella F, et al. Echocardiographic screening discloses increased values of pulmonary artery systolic pressure in 9 of 68 unselected patients affected with hereditary hemorrhagic telangiectasia. Genet Med 2006; 8: 183-190.

57 Colle IO, Moreau R, Godinho E, et al. Diagnosis of portopulmonary hypertension in candidates for liver transplantation: a prospective study. Hepatology 2003; 37: 401-409.

58 Deng Z, Morse JH, Slager SL, et al. Familial primary pulmonary hypertension (gene PPH1) is caused by mutations in the bone morphogenetic protein receptor-II gene. Am J Hum Genet 2000; 67: 737-744.

59 Machado RD, Pauciulo MW, Thomson JR, et al. BMPR2 haploinsufficiency as the inherited molecular mechanism for primary pulmonary hypertension. Am J Hum Genet 2001; 68: 92-102.

60 Machado RD, Aldred MA, James V, et al. Mutations of the TGF- $\beta$ type II receptor BMPR2 in pulmonary arterial hypertension. Hum Mutat 2006; 27: 121-132.

61 Sztrymf B, Coulet F, Girerd B, et al. Clinical outcomes of pulmonary arterial hypertension in carriers of BMPR2 mutation. Am J Respir Crit Care Med 2008; 177: 1377-1383.

62 Trembath RC, Thomson JR, Machado RD, et al. Clinical and molecular genetic features of pulmonary hypertension in patients with hereditary hemorrhagic telangiectasia. $N$ Engl J Med 2001; 345: 325-334.

63 Harrison RE, Flanagan JA, Sankelo M, et al. Molecular and functional analysis identifies ALK-1 as the predominant cause of pulmonary hypertension related to hereditary haemorrhagic telangiectasia. J Med Genet 2003; 40: 865-871.

64 Chaouat A, Coulet F, Favre C, et al. Endoglin germline mutation in a patient with hereditary haemorrhagic telangiectasia and dexfenfluramine associated pulmonary arterial hypertension. Thorax 2004; 59: 446-448.

65 Fernandez LA, Sanz-Rodriguez F, Zarrabeitia R, et al. Mutation study of Spanish patients with hereditary hemorrhagic telangiectasia and expression analysis of endoglin and ALK1. Hum Mutat 2006; 27: 295.

66 Harrison RE, Berger R, Haworth SG, et al. Transforming growth factor- $\beta$ receptor mutations and pulmonary arterial hypertension in childhood. Circulation 2005; 111: 435-441.

67 Seki T, Hong KH, Yun J, Kim SJ, Oh SP. Isolation of a regulatory region of activin receptor-like kinase 1 gene sufficient for arterial endothelium-specific expression. Circ Res 2004; 94: e72-e77.

68 Bobik A. Transforming growth factor- $\beta$ s and vascular disorders. Arterioscler Thromb Vasc Biol 2006; 26: 1712-1720.

69 Howe JR, Chinnathambi S, Calva D, et al. A family with two consecutive nonsense mutations in BMPR1A causing juvenile polyposis. Cancer Genet Cytogenet 2008; 181: 52-54.

70 Varnholt H, Kradin R. Pulmonary capillary hemangiomatosis arising in hereditary hemorrhagic telangiectasia. Hum Pathol 2004; 35: 266-268.

71 Shovlin CL, Tighe HC, Davies RJ, Gibbs JSR, Jackson JE. Embolisation of pulmonary arteriovenous malformations: no consistent effect on pulmonary artery pressure. Eur Respir J 2008; 32: 162-169.

72 Mache CJ, Gamillscheg A, Popper HH, Haworth SG. Earlylife pulmonary arterial hypertension with subsequent development of diffuse pulmonary arteriovenous malformations in hereditary haemorrhagic telangiectasia type 1 . Thorax 2008; 63: 85-86.

73 Galie N, Ghofrani HA, Torbicki A, et al. Sildenafil citrate therapy for pulmonary arterial hypertension. $N$ Engl J Med 2005; 353: 2148-2157.

74 Barst RJ, Rubin LJ, Long WA, et al. A comparison of continuous intravenous epoprostenol (prostacyclin) with conventional therapy for primary pulmonary hypertension. The Primary Pulmonary Hypertension Study Group. N Engl J Med 1996; 334: 296-301.

75 Minai OA, Sahoo D, Chapman JT, Mehta AC. Vaso-active therapy can improve 6-min walk distance in patients with pulmonary hypertension and fibrotic interstitial lung disease. Respir Med 2008; 102: 1015-1020. 